\title{
Capsaicin triggers autophagic cell survival which drives epithelial mesenchymal transition and chemoresistance in bladder cancer cells in an Hedgehog-dependent manner
}

\author{
Consuelo Amantini ${ }^{1}$, Maria Beatrice Morelli ${ }^{2,3}$, Massimo Nabissi ${ }^{2}$, Claudio \\ Cardinali ${ }^{2,3}$, Matteo Santoni ${ }^{4}$, Angela Gismondi ${ }^{3}$, Giorgio Santoni ${ }^{2}$ \\ ${ }^{1}$ School of Biosciences and Veterinary Medicine, University of Camerino, Camerino, Italy \\ ${ }^{2}$ School of Pharmacy, Experimental Medicine Section, University of Camerino, Camerino, Italy \\ ${ }^{3}$ Department of Molecular Medicine, Sapienza University, Rome, Italy \\ ${ }^{4}$ Department of Medical Oncology, Polytechnic University of Marche, Ancona, Italy \\ Correspondence to: Giorgio Santoni, email: giorgio.santoni@unicam.it \\ Keywords: capsaicin, bladder cancer, autophagy, EMT, Hedgehog pathway \\ Received: May 13,2016 Accepted: June 13,2016 Published: June 29, 2016
}

\section{ABSTRACT}

Bladder cancer (BC) is a common urologic tumor characterized by high risk of recurrence and mortality. Capsaicin (CPS), used as an intravesical drug for overactive bladder, was demonstrated to induce cell death in different cancer cells including BC cells.

Here we found that treatment of high-grade BC cells with high dose of CPS triggers autophagy. Infact, the CPS treatment alters the redox homeostasis by inducing production of radicals, mitochondrial depolarization, alterations of ADP/ ATP ratio and activation of AMPK pathway stimulating the autophagic process in BC cells. The inhibition of autophagy, by using the specific inhibitor bafilomycin $A$ or Beclin 1 knock-down, enhanced the CPS-induced cell death, demonstrating that CPS-induced autophagy acts as a pro-survival process in BC cells. By using PCR arrays and FACS analysis, we found that the CPS-treated BC cells displayed typical mesenchymal features of the epithelial mesenchymal transition (EMT) as elongated shape and over-expression of vimentin, $\alpha_{5}$ and $\beta_{1}$ integrin subunits, integrin-like kinase and the anti-apoptotic Bcl-2 proteins. Moreover, we demonstrated that CPS treatment stimulates upregulation of Dhh/Ptch2/Zeb2 members of the Hedgehog signaling pathway, increases CD24, VEGFA and TIMP1 and decreases CD44 and ALCAM mRNA expression levels. By PTCH2 knock-down we found that the Hedgehog signaling pathway is involved in the CPS-induced autophagy and EMT phenotype.

Finally, we also showed that the CPS-resistant EMT-positive BC cells displayed an increased drug-resistance to the cytotoxic effects of mitomycin $C_{\text {, gemcitabine and }}$ doxorubicine drugs commonly used in BC therapy.

\section{INTRODUCTION}

Bladder cancer $(\mathrm{BC})$, characterized by high risk of recurrence and mortality, is among the fifth most common malignancies in the world. The majority of BC is represented by urothelial carcinoma (UC), also known as transitional cell carcinoma (TCC), while squamous and adenocarcinomas are diffused in a small percentage [1]. Although $\mathrm{BC}$ is considered to be responsive to the chemotherapy regiments, only few patients respond to single-agent therapy. For this reason, the finding of innovative anti-cancer combinations and new antineoplastic drugs is necessary.

Capsaicin (CPS), mainly known as food additive, is the active alkaloid found primarily in the chili peppers of the plant genus Capsicum, responsible for the hot pungent taste of these fruits. CPS, its derivatives and related compounds form a chemical group called 
capsaicinoids, known as exciting pharmacological agents for their ability to exert various effects on human body and in different diseases such as obesity, cardiovascular, gastrointestinal, dermatologic conditions and neurogenic overactive bladder [2]. In the last decades, several reports have demonstrated that CPS treatment is able to induce both pro- and anti-carcinogenic effects [3]. In fact, CPS inhibits cell proliferation and induces cell death in a TRPV1dependent and independent manner in many different malignant human cell lines [4-6], including prostate and BC cells [7-9]; on the contrary, CPS promotes the carcinogenesis of colon, gastric and skin cancers stimulating cell proliferation and migration [2].

Autophagy is a self-degradative cellular mechanism used to degrade and recycle cytoplasmic components to provide energy during starvation, stress conditions or growth factor withdrawal promoting cell survival; however, excessive autophagy may also trigger autophagic-associated cell death [10]. It has been shown that CPS is able to stimulate autophagy in breast cancer and osteosarcoma cell lines. The CPS-induced autophagy is evoked at the same time with cell death and involves the DNA repair system functioning as a pathway that counteracts the CPS-induced apoptosis prolonging cancer cell survival $[11,12]$. Moreover, several reports demonstrated that autophagy inhibition sensitizes $\mathrm{BC}$ cells to chemotherapy, indicating that in $\mathrm{BC}$, targeting autophagy may be an effective therapeutic strategy to overcome drug resistance [13].

Novel evidence suggests that drug resistance is acquired by BC cells that undergo epithelial mesenchymal transition (EMT). EMT, characterized by morphological and molecular changes of cancer cells with increase of mesenchymal-related proteins, plays a pivotal role in the acquisition of malignant features such as invasion, metastasis and chemoresistance $[14,15]$. In this regard, CPS induces EMT in colon cancer cells by modulating the reactive oxygen species (ROS) production and the AKT/ mTOR pathways [16].

In $\mathrm{BC}$, the tumorigenicity and EMT process are regulated through constitutive activation of different members of the Hedgehog (Hh) signaling pathway [17, 18]. Three Hh genes have been described in mammals: Sonic (SHH), Indian (IHH) and Desert (DHH). The Hh proteins are ligands for the patched receptor (Ptch), which negatively regulates smoothened protein (Smo). The Ptch binds to the Hh proteins, resulting in Ptch internalization in endosomes and lifting Ptch-mediated repression. Two homologous Ptch receptors, Ptch1 and Ptch2, have been described, both of which are able to interact with the Hh ligands [19].

Herein, the ability of CPS to induce autophagic cell survival, EMT and chemoresistance by involving the Hedgehog pathway was investigated in BC cell lines.

\section{RESULTS}

\section{CPS induces autophagy in BC cells}

The activation of autophagy in CPS (300 $\mu \mathrm{M})$ treated BC cells was evaluated by assessing the processing of LC3 protein by western blot analysis. To this purpose, 5637 and T24 cancer cells, treated or not with CPS for different times, were analyzed for LC3 mobility. A significant accumulation of LC3-II proteins, starting at $12 \mathrm{~h}$ after treatment and sustained until $72 \mathrm{~h}$ was observed in both CPS-treated BC cell lines (Figure 1A). Similar results were obtained treating BC cells with rapamycin used as a positive control (data not shown). In addition, enhanced protein expression of sequestosome 1 (p62/SQSTM1), involved in the delivery of autophagic substrates and nucleation of autophagosomes was observed by western blot analysis in CPS-treated BC cells (Figure 1A). Since some autophagy inducers exert their effects both at p62 synthesis and degradation levels [20], p62 levels were also evaluated in BC cells treated with CPS in combination with the lysosomial inhibitor bafilomycin A (BAF, $25 \mathrm{nM}$ ). As shown in Figure $1 \mathrm{~B}, \mathrm{BAF}$ increased the p62 level in CPS-treated cells demonstrating the ability of CPS to induce an autophagic flux in BC cells. Similar results were obtained for LC3II levels (Figure 1B). The CPS-induced autophagy was further confirmed by acridine orange (AO) staining and FACS analysis. A marked formation of acidic vesicular organelles (AVOs), a morphological characteristic of the autophagic process, was observed in CPS-treated BC cells respect to untreated cells (Figure 1C).

\section{CPS induces oxidative stress that triggers autophagy in $\mathrm{BC}$ cells}

The energy sensor AMPK acts as a major regulator of cellular ATP levels and protects cells against stresses. Recent evidence demonstrated that activation of AMPK by calcium and ROS signalling inhibits the mTOR complex and induces autophagy [21]. Thus, we evaluated the AMPK activation by measuring its phosphorylation status (pAMPK), reactive oxygen species (ROS) generation, the mitochondrial depolarization and ATP levels in untreated and CPS $(300 \mu \mathrm{M})$-treated BC cells. Time-course immunoblot analysis showed that enhancement of pAMPK was evident at $1 \mathrm{~h}$, peaked at 3 and $6 \mathrm{~h}$ after CPS exposure, remaining sustained at later time-points (Figure 2A).

ROS signals and mitochondrial alterations have been associated to vanilloid-mediated effects [22]. Thus, the involvement of ROS production during stress-induced autophagy was evaluated in CPS-treated $\mathrm{BC}$ cells by cytofluorimetric analysis. We found that CPS treatment induces ROS generation in BC cells, 
with a sustained accumulation which begins at $8 \mathrm{~h}$ and increases at later time-points (Figure 2B). The ROS scavenger $\mathrm{N}$ acetylcysteine (NAC, $10 \mathrm{mM}$ ) completely inhibited ROS production, indicating that CPS stimulates peroxide accumulation in BC cells (Figure 2C). Moreover, to better assess the source of CPS-induced ROS generation, BC cells were treated with CPS alone or in combination with the mitochondrial respiratory chain inhibitor rotenone (ROT, $1 \mu \mathrm{M})$ or the NAD $(\mathrm{P}) \mathrm{H}$ oxidase inhibitor diphenyleneiodonium (DPI, $0.1 \mu \mathrm{M}$ ). As shown in Figure 2C, ROT and DPI markedly reduced ROS production indicating that CPS treatment affects both the mitochondrial respiration and the membranebound enzyme complex (Figure 2C). Since mitochondrial dysfunction is often associated with ROS generation, we used JC-1 labeling and cytofluorimeter to analyze $\Delta \Psi \mathrm{m}$ in

A
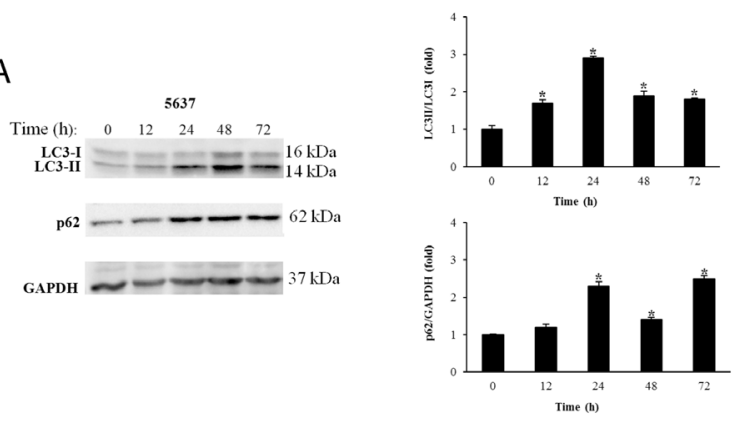

B
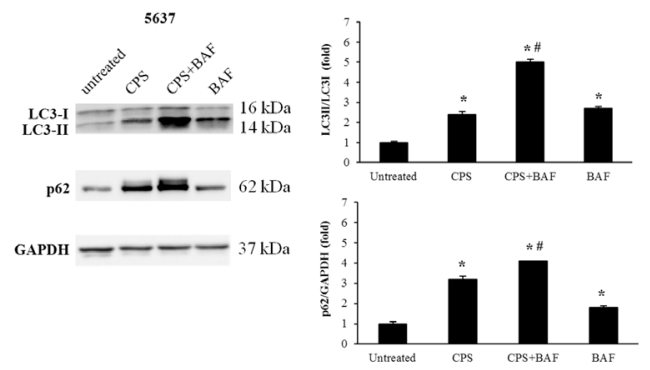

C

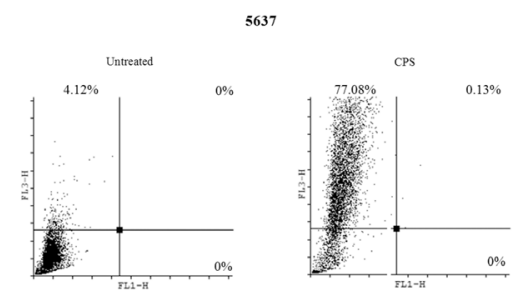

5637 and T24 BC cells. We found that treatment with CPS induces a time-dependent decrease of red fluorescence (depolarization). The CPS-induced $\Delta \Psi \mathrm{m}$ dissipation was evident at $6 \mathrm{~h}$, increased at $12 \mathrm{~h}$ and remained sustained at $24 \mathrm{~h}$ (Figure 2D). Changes in ADP/ATP ratio are indicative of alterations in energy metabolism. By using bioluminescent assay, we also demonstrated that the ADP/ ATP ratio is increased in CPS-treated as compared with untreated cells (Figure 2E).

The cysteine protease Atg $4 \mathrm{C}$, regulated by ROS generation, is involved in the formation and maturation of autophagosomes and represents the main cellular target of oxidative signals in CPS-induced autophagy [23]. Herein we found that CPS increases at 1-6 and 12-24 h the expression of Atg4C protein in T24 and $5637 \mathrm{BC}$ cells, respectively (Figure 2F). Finally, by western blot analysis,
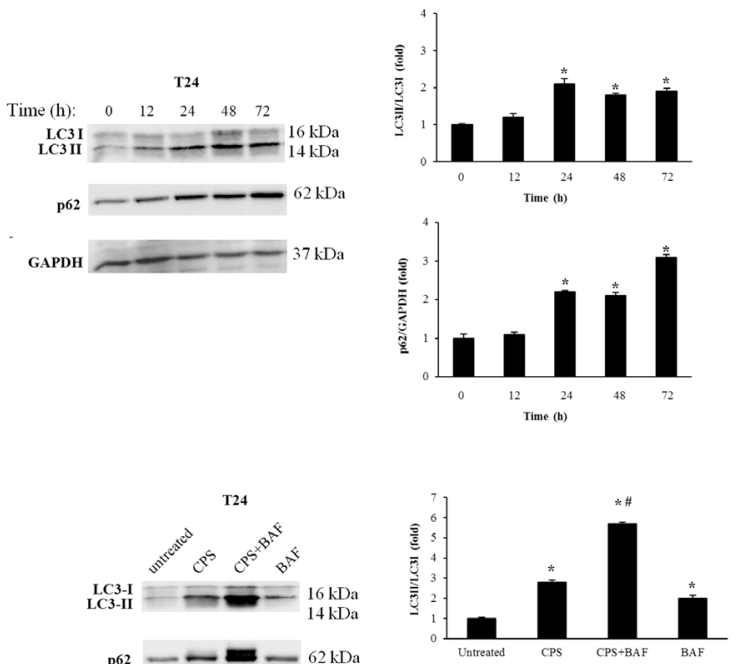

GAPDH $--\longrightarrow 37 \mathrm{kDa}$

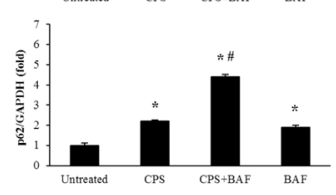

T24

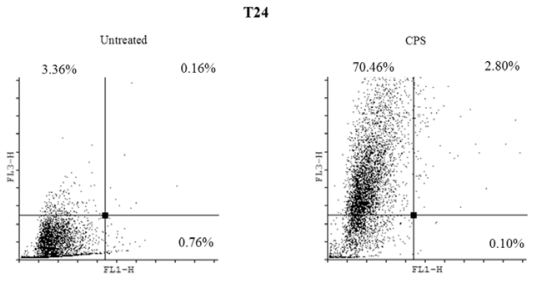

Figure 1: The CPS treatment triggers autophagy in BC cells. A. Lysates from BC cells, untreated or treated for different times with CPS $(300 \mu \mathrm{M})$ were separated on $14 \%$ or $8 \%$ SDS-PAGE and probed with anti-LC3 and anti-p62 Abs respectively. GAPDH protein levels were evaluated as loading control. Cropped blots are representative of one out of three separate experiments. Bars represent the densitometric analysis, shown as the mean \pm SD of three different experiments, evaluated using untreated cells as calibrator. ${ }^{*} p<0.01$ CPStreated cells vs untreated. B. Lysates from BC cells, untreated or treated for $12 \mathrm{~h}$ with CPS $(300 \mu \mathrm{M})$ alone or in combination with BAF $(25$ $\mathrm{nM}$ ) were separated on $14 \%$ or $8 \%$ SDS-PAGE and probed with anti-LC3 and anti-p62 Abs respectively. GAPDH protein levels were used as loading control. Cropped blots are representative of one of three separate experiments. Bars represent the densitometric analysis, shown as the mean \pm SD of three different experiments, evaluated using untreated cells as calibrator. ${ }^{*} p<0.01$ vs untreated; \#p $<0.01$ CPS $+B A F-v s$ CPS or BAF-treated cells. C. AVOs were evaluated by AO staining and cytofluorimentric analysis in BC cells untreated or treated with CPS $(300 \mu \mathrm{M})$ for $48 \mathrm{~h}$. Dot plots are representative of one out of three separate experiments. 
A

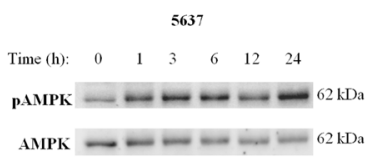

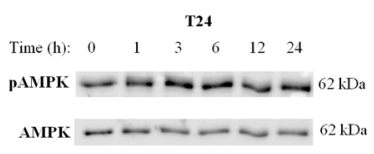

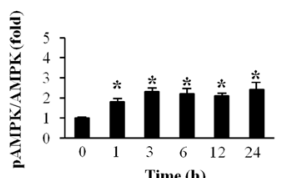

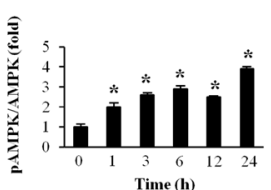

Time (h)

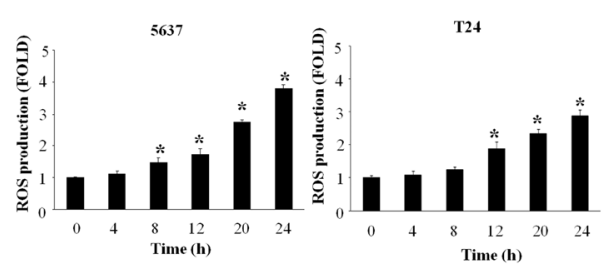

C

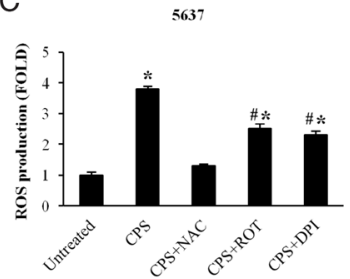

T24

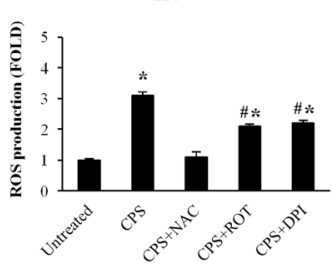

D
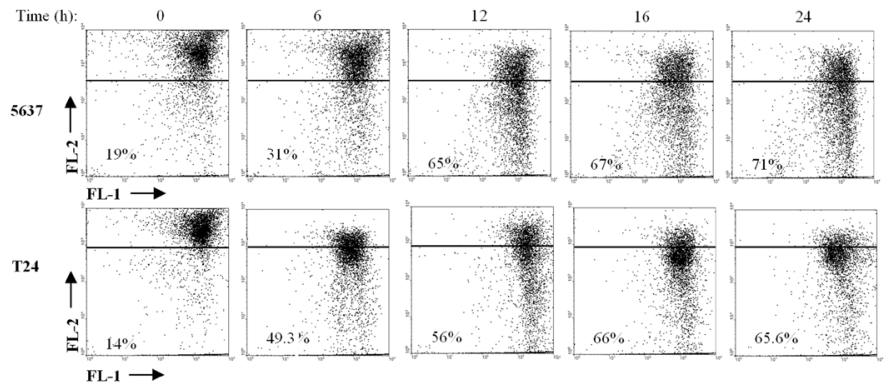

E

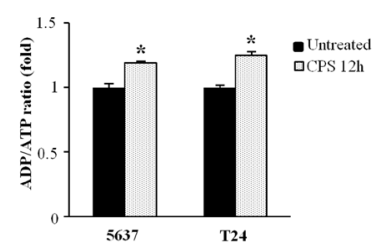

F
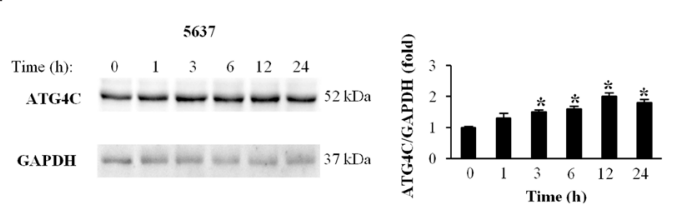

G
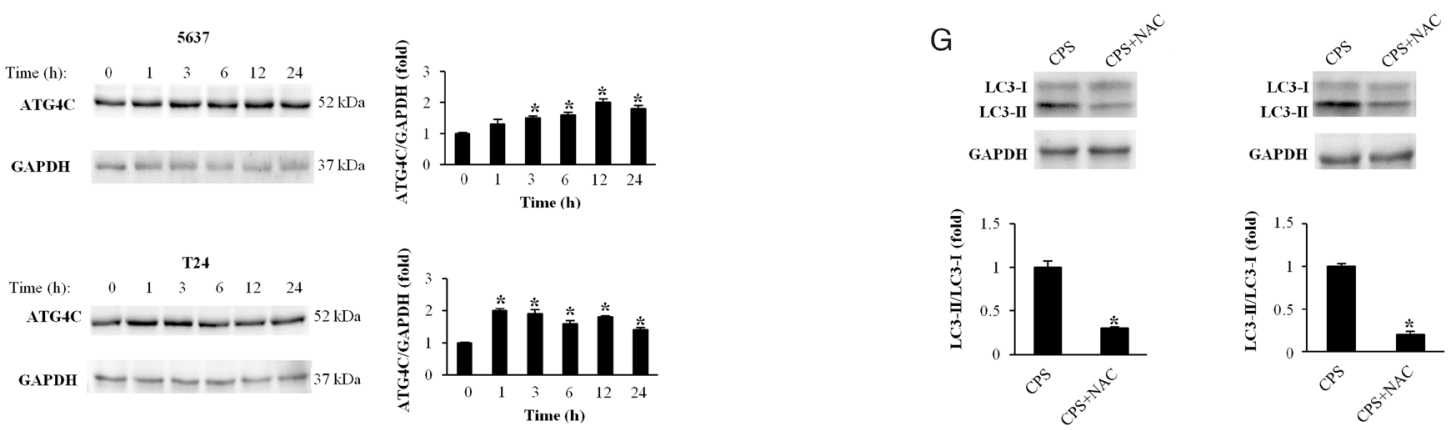

Figure 2: CPS triggers ROS production altering the mitochondrial redox homeostasis in $\mathrm{BC}$ cells. $\mathrm{A}$. Lysates from $\mathrm{BC}$ cells, untreated or treated for different times with CPS $(300 \mu \mathrm{M})$ were separated on 10\% SDS-PAGE and probed with anti-pAMPK mAb and anti-AMPK Ab. Cropped blots are representative of one of three separate experiments. Bars represent the densitometric analysis, shown as the mean $\pm \mathrm{SD}$ of three different experiments, evaluated using untreated cells as calibrator. ${ }^{*} \mathrm{p}<0.01 \mathrm{CPS}$-treated vs untreated cells. B. ROS production was evaluated by DCFDA staining and cytofluorimetric analysis in 5637 and T24 cells treated for different times with CPS $(300 \mu \mathrm{M})$. Data, shown as the mean \pm SD of three independent experiments, are expressed as fold change with respect of ROS basal level. ${ }^{*} \mathrm{p}<0.01$, CPS-treated vs untreated cells.C. ROS production was evaluated as above described in BC cells treated for $24 \mathrm{~h}$ with CPS $(300 \mu \mathrm{M})$ alone or in combination with NAC $(10 \mathrm{mM})$, ROT $(1 \mu \mathrm{M})$ or DPI $(0.1 \mu \mathrm{M})$. Data, shown as the mean \pm SD of three independent experiments, are expressed as fold change with respect of ROS basal level. ${ }^{*} \mathrm{p}<0.01 \mathrm{CPS}-$, CPS + ROT or CPS $+\mathrm{DPI}-$ treated vs untreated cells; $\# \mathrm{p}<0.01$ CPS+ROT or CPS+DPI-treated vs CPS-treated cells. D. Time course analysis of $\Delta \Psi \mathrm{m}$ changes in 5637 and T24 cells untreated or treated for different times with CPS $(300 \mu \mathrm{M})$, was evaluated by JC-1 staining and biparametric FL1 (green)/FL2(red) flow cytometric analysis. Numbers indicate the percentage of cells showing a drop in $\Delta \Psi$ m-related red fluorescence intensity. Data are representative of one out of three separate experiments. E. ADP/ATP ratio in T24 and 5637 cells, untreated or treated with CPS (300 $\mu \mathrm{M})$ for $12 \mathrm{~h}$, was evaluated by bioluminescent assay. Data are the mean $\pm \mathrm{SD}$ of three independent experiments. *p $<0.01 \mathrm{CPS}$-treated vs untreated cells. F. Lysates from BC cells, treated as described in panel A, were separated on 10\% SDS-PAGE and probed with Atg4C or anti-GAPDH Abs. Cropped blots are representative of one of three separate experiments. Bars represent the densitometric analysis, shown as the mean \pm SD of three different experiments, evaluated using untreated cells as calibrator $* p<0.01$ CPS-treated vs untreated cells. G. Lysates from BC cells, treated for $72 \mathrm{~h}$ with CPS $(300 \mu \mathrm{M})$ alone or in combination with NAC $(10 \mathrm{mM})$ were separated on 14\% SDS-PAGE and probed with anti-LC3 Ab. GAPDH protein levels were used as loading control. Bars represent the densitometric analysis, shown as the mean \pm SD of three different experiments, evaluated using CPS-treated cells as calibrator. ${ }^{*} \mathrm{p}<0.01 \mathrm{CPS}+\mathrm{NAC}$ - vs CPS-treated cells. 
Table 1: CPS stimulates the autophagic signaling pathway in $\mathrm{BC}$ cells

\begin{tabular}{|c|c|c|c|c|}
\hline \multirow{2}{*}{ Gene Bank ID } & \multirow{2}{*}{ Symbol } & \multirow{2}{*}{ Description } & \multicolumn{2}{|c|}{ Fold change } \\
\hline & & & 5637 cell line & T24 cell line \\
\hline NM_003824 & FADD & $\begin{array}{l}\text { Fas (TNFRSF6)-associated via death } \\
\text { domain }\end{array}$ & -2.01 & -1.78 \\
\hline NM_031412 & GABARAPL1 & $\begin{array}{l}\text { GABA(A) receptor-associated } \\
\text { protein like } 1\end{array}$ & 3.59 & 1.74 \\
\hline NM_001017963 & HSP90AA1 & $\begin{array}{l}\text { Heat shock protein } 90 \mathrm{kDa} \text { alpha } \\
\text { (cytosolic), class A member } 1\end{array}$ & -1.13 & 2.31 \\
\hline NM_000618 & IGF1 & $\begin{array}{l}\text { Insulin-like growth factor } 1 \\
\text { (somatomedin C) }\end{array}$ & -12.77 & -3.07 \\
\hline NM_001145805 & IRGM & Immunity-related GTPase family, M & 3.28 & 1.13 \\
\hline NM_022818 & MAP1LC3B & $\begin{array}{l}\text { Microtubule-associated protein } 1 \\
\text { light chain } 3 \text { beta }\end{array}$ & 2.20 & 2.69 \\
\hline NM_000314 & PTEN & Phosphatase and tensin homolog & 4.10 & 1.13 \\
\hline NM_003900 & SQSTM1 & Sequestosome 1 & 2.69 & 1.79 \\
\hline NM_000594 & TNF & Tumor necrosis factor & 7.54 & 8.34 \\
\hline NM_003565 & ULK1 & Unc-51-like kinase 1 (C. elegans) & 2.52 & 1.41 \\
\hline NM_005427 & TP73 & Tumor protein p73 & -1.74 & -2.17 \\
\hline
\end{tabular}

Autophagy RT profiler PCR array in mRNA samples extracted from 5637 and T24 BC cells treated for $12 \mathrm{~h}$ with vehicle or CPS $(300 \mu \mathrm{M})$. Values represent fold differences of individual gene expression in CPS- compared to vehicle-treated BC cells. The expression levels were normalized to the average $\mathrm{Ct}$ value of two housekeeping genes (GAPDH and RPLP0) and calculated by the $\Delta \Delta \mathrm{Ct}$ method. In bold up-regulated genes. Data shown are representative of one out of three separate experiments.

we demonstrated that the ROS inhibitor, NAC (10 mM) reverted the CPS-induced autophagy (Figure 2G). NAC alone did not induce changes in the LC3 levels respect to untreated cells (Supplementary Figure 1A). Overall, our data demonstrated in BC cells that CPS treatment alters the mitochondrial redox homeostasis and induces autophagy in a ROS dependent manner.

Finally to evaluate the effects of CPS on autophagic gene pathway, we performed a RT Profiler array comparing untreated with CPS-treated BC cells at $12 \mathrm{~h}$ after treatment. We found that GABARAPL1, MAP1LC3B, SQSTM1, IRGM, ULK1, TNF and PTEN genes mediating different steps of the autophagic process were strongly upregulated and FADD and TP73, involved in the apoptotic pathway and IGF1, implicated in cell proliferation, were downregulated (Table 1).

\section{CPS-induced autophagy acts as pro-survival mechanism in BC cells}

In cancer, autophagy is generally thought to play a pro-survival role allowing cancer cells to survive during metabolic stress; however excessive autophagy can also induce cell death [10]. To better understand the role of CPS-induced autophagy, we evaluated, by cytofuorimetric analysis, cell death/survival in BC cells treated for different times with CPS $(300 \mu \mathrm{M})$ in the presence or not of the autophagic inhibitor BAF (25 $\mathrm{nM})$. By PI and annexin V staining, we found that CPS induces necrotic cell death in a time-dependent manner in 5637 and T24 BC cells, and that BAF enhances the CPS-induced cytotoxic effects (Figure 3A and 3B).

Moreover, since a pivotal role of Atg6/Beclin-1 in autophagy, we knocked-down Beclin 1 gene (siBeclin 1 ) in $\mathrm{BC}$ cells. As shown in Figure $3 \mathrm{C}$, Beclin 1 protein expression was strongly down regulated in siBeclin 1, compared with control-BC cells ( and siGLO BC cells were treated with CPS for $72 \mathrm{~h}$ and cell growth was evaluated by MTT assay. Interestingly, knock-down of Beclin 1, that abrogates CPS-induced autophagy (Figure 3D), strongly reduced BC cell growth (Figure 3E). Overall, these results demonstrated a survival role for CPS-induced autophagy in BC cells. 


\section{CPS-induced autophagy triggers epithelial mesenchymal transition (EMT) in BC cells}

Since the CPS-induced autophagy acts as a prosurvival process, BC cells were treated with CPS (300 $\mu \mathrm{M})$ for 72 and $120 \mathrm{~h}$ to assess the proliferative capability by MTT and BrdU incorporation. Our results evidenced that CPS-resistant BC cells are actively replicating (Figure $4 \mathrm{~A}$ and $4 \mathrm{~B}$ ), suggesting that they could be responsible for bladder cancer relapse.

Then, we better characterized the phenotype of CPSresistant BC cells at $120 \mathrm{~h}$ after CPS treatment by light microscopy and cytofluorimetric analysis. As shown in Figure 4C and Supplementary Figure 1B, CPS-treated BC cells, displayed an increased cell size and morphological changes with a conversion from a "cuboidal" epithelial structure into an elongated mesenchymal shape, compared to untreated cells, suggesting that prolonged exposure to CPS stimulates the EMT process in BC cells. To further address the presence of the EMT phenomenon in CPSresistant $\mathrm{BC}$ cells, we investigated the expression of markers typical of the epithelial mesenchymal transition. Our results showed that the expression of E-cadherin is

significantly reduced in CPS-treated cells, respect to untreated $\mathrm{BC}$ cells, whereas vimentin, $\alpha_{5}$ and $\beta_{1}$ integrin subunits, ILK and Bcl-2 are upregulated (Figure 4D), indicating the occurrence of EMT and the acquisition of a more aggressive phenotype in CPS-resistant BC cells.

\section{CPS induces autophagy and EMT in an Hedgehog signaling pathway dependent manner}

The Hedgehog pathway has been found to regulate autophagy and EMT [24-26]. Thus, we first evaluated by quantitative real time PCR (qRT-PCR) the expression of different members of Hedgehog signaling pathway, Shh, Ihh and Dhh ligands, their specific receptors, Patched 1 and 2 (Ptch1 and Ptch2) and some related genes such as Zeb1, Zeb2, ALCAM and VEGFA in BC cells treated with CPS for $120 \mathrm{~h}$. Upregulation of the Dhh/Ptch2/Zeb2 pathway as well as downregulation of Shh or Ihh/Ptch1/ Zeb1 genes were observed in CPS-treated BC cells as respect to untreated cells. In addition, increased CD24, VEGFA and TIMP1 and decreased CD44 and ALCAM mRNA levels were found in both T24 and 5637 BC cell lines (Table 2).
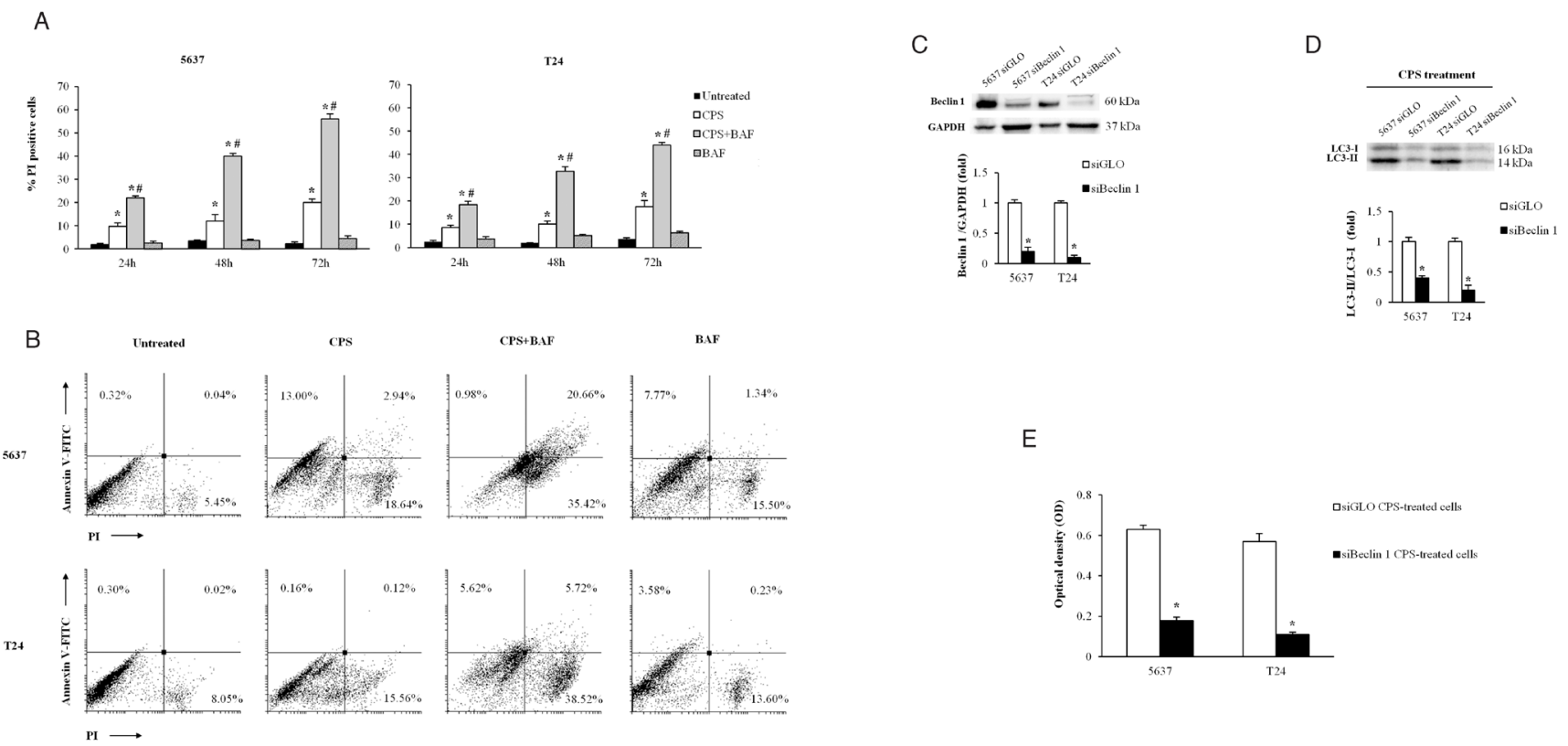

Figure 3: The CPS-induced autophagy acts as a pro-survival process in BC cells. A. Cell death was evaluated in BC cells, untreated or treated for different times with CPS $(300 \mu \mathrm{M})$ alone or in combination with BAF $(25 \mathrm{nM})$ by FACS analysis. Data shown are the mean \pm SD of three independent experiments. ${ }^{*} p<0.01$ vs untreated; $\# p<0.01$ CPS plus BAF vs CPS- or BAF-treated cells. B. Cell death type was determined by Annexin V/PI staining and cytofluorimetric analysis in BC cells after $72 \mathrm{~h}$ of treatment with CPS (300 $\mu \mathrm{M})$ alone or in combination with BAF $(25 \mathrm{nM})$. Data are representative of one out of three separate experiments. Numbers represent the percentage of positive cells. C. Lysates from siGLO and siBeclin $1 \mathrm{BC}$ cells were separated on 8\% SDS-PAGE and probed with anti-Beclin $1 \mathrm{Ab}$. Cropped blots are representative of one of three separate experiments. Bars represent the densitometric analysis, shown as the mean \pm SD of three different experiments, evaluated using siGLO cells as calibrator. ${ }^{*} p<0.01$ siBeclin 1 vs siGLO cells. D. Lysates from siGLO and siBeclin $1 \mathrm{BC}$ cells treated for $72 \mathrm{~h}$ with CPS $(300 \mu \mathrm{M})$ were separated on 14\% SDS-PAGE and probed with anti-LC3 Ab. Cropped blots are representative of one of three separate experiments. Bars represent the densitometric analysis, shown as the mean $\pm \mathrm{SD}$ of three different experiments, evaluated using siGLO cells as calibrator. ${ }^{*} \mathrm{p}<0.01$ CPS-treated siBeclin 1 vs CPS-treated siGLO cells. E. Cell viability was assessed by MTT assay in siGLO and siBeclin $1 \mathrm{BC}$ cells treated for $72 \mathrm{~h}$ with CPS $(300 \mu \mathrm{M})$. Data shown are the mean \pm SD of three independent experiments. ${ }^{*} \mathrm{p}<0.01$ siBeclin 1 vs siGLO CPS-treated BC cells. 
To better investigate the role of the Hedgehog pathway, BC cells were silenced for PTCH2 ( $\mathrm{PiPTCH} 2$ ). A reduction of $\mathrm{PTCH} 2 \mathrm{mRNA}$ was observed in siPTCH2 as respect to siGLO (control) BC cells (Figure 5A). Therefore, we treated silenced BC cells with CPS for 72 and $120 \mathrm{~h}$ to assess autophagy and EMT transition, respectively. Our results showed that the LC3II/LC3I ratio is reduced in siPTCH2 compared with siGLO $\mathrm{BC}$ cells (Figure 5B) and more interestingly, FACS analysis displayed that PTCH2 knockdown decreased the expression of vimentin and $\alpha_{5}$ integrin subunit in CPS-treated cells. Overall our findings demonstrated that the Hedgehog signaling pathway is involved in CPS-induced autophagy and EMT phenotype in BC cells.

A

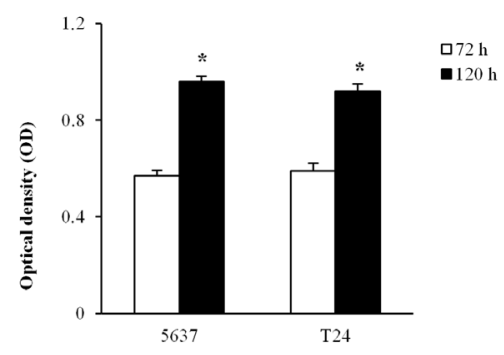

B

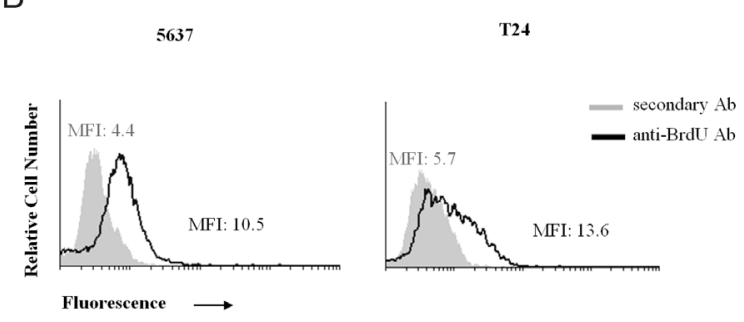

C

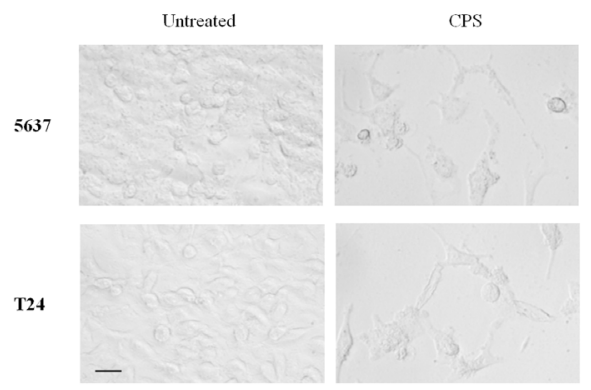

The EMT, induced by CPS, promotes chemotherapeutic drug-resistance of $\mathrm{BC}$ cells

Hedgehog signaling pathway activation is positively correlated with chemoresitance in cancer cells [24, 27]. Thus, we finally investigated the drug-sensitivity of CPS-induced EMT cells to chemotherapeutic agents commonly used in BC therapy. To this purpose, CPS-exposed $(120 \mathrm{~h}) \mathrm{BC}$ cells, were further treated for additional $48 \mathrm{~h}$ with different doses of mitomycin $\mathrm{C}$, gemcitabine and doxorubicine. As shown in Figure 6A and 6B, the CPS-resistant BC cells were significantly less sensitive to chemotherapeutic agents compared with untreated cells. In fact the $\mathrm{IC}_{50}$ resulted about two-three fold higher for all tested drugs in CPS-treated BC cells respect to untreated cells.

D
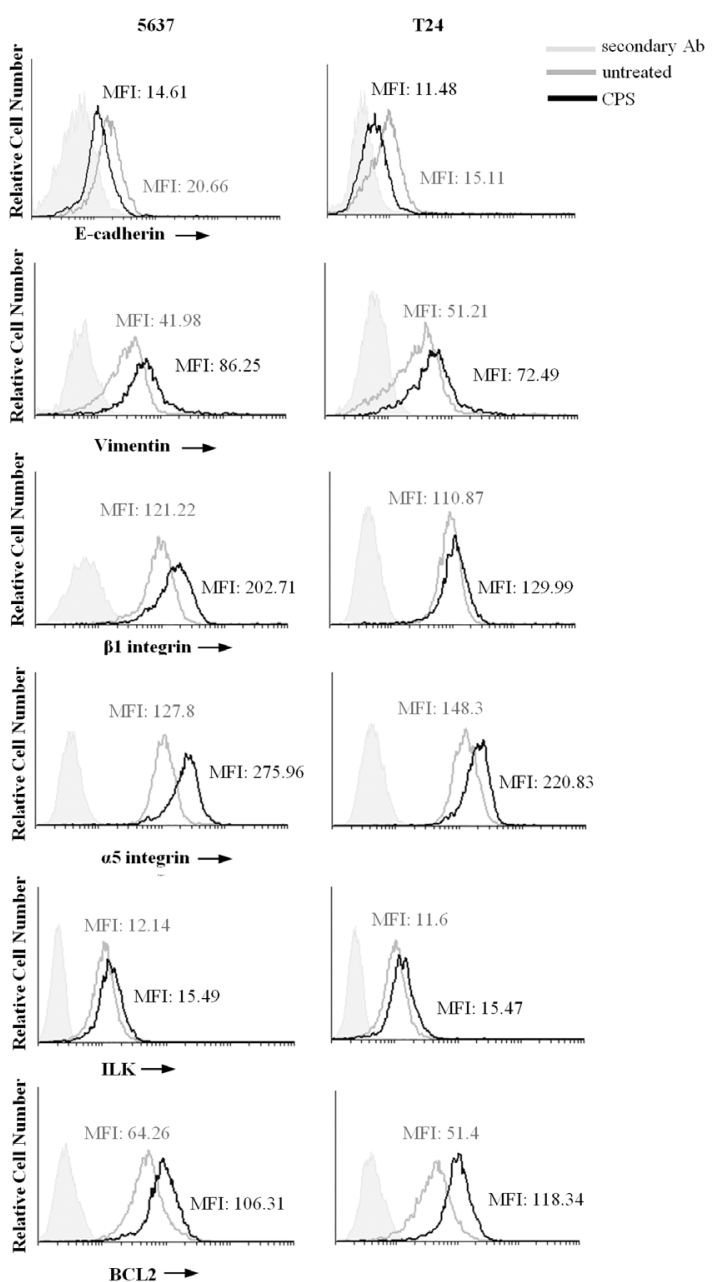

Figure 4: The CPS-resistant BC cells display the EMT phenotype. A. Cell growth was assessed by MTT assay in 5637 and T24 $\mathrm{BC}$ cells treated for $72 \mathrm{~h}$ or $120 \mathrm{~h}$ with CPS $(300 \mu \mathrm{M})$. Data shown are the mean $\pm \mathrm{SD}$ of three independent experiments. $* \mathrm{p}<0.01120 \mathrm{~h}$ CPS-treated vs $72 \mathrm{~h}$ CPS-treated BC cells.B. Cell replication was assessed by BrdU incorporation and FACS analysis in BC cells treated for $120 \mathrm{~h}$ with CPS $(300 \mu \mathrm{M})$ and cultured in medium for additional $24 \mathrm{~h}$. One representative out of three independent experiments is shown. Numbers indicate the Mean Fluorescence Intensity (MFI).C. Cell morphology was evaluated by light microscopy in BC cells, untreated or treated with CPS $(300 \mu \mathrm{M})$ for $120 \mathrm{~h}$. One representative out of three independent experiments is shown. Bar $=25 \mu \mathrm{M}$. D. FACS analysis was performed in BC cells, untreated or treated with CPS $(300 \mu \mathrm{M})$ for $120 \mathrm{~h}$, stained with anti-E cadherin, anti-vimentin, anti- $\beta_{1}$ and anti- $\alpha_{5}$ integrin subunits, anti-ILK and anti-Bcl 2 Abs followed by respective FITC-conjugated secondary Abs. One representative out of three independent experiments is shown. Numbers indicate the Mean Fluorescence Intensity (MFI). 
Table 2: CPS treatment influences the Hedgehog and EMT pathways

\begin{tabular}{llllcc}
\hline \multirow{2}{*}{ Assay ID } & Gene Bank ID & Symbol & Description & \multicolumn{2}{c}{ Fold change } \\
\cline { 5 - 6 } Hs03044178_g1 & NM_013230 & CD24 & CD24 & $\mathbf{5 6 3 7}$ cell line & T24 cell line \\
Hs01075861_m1 & NM_000610 & CD44 & CD44 & $\mathbf{1 . 9 5}$ \\
Hs00179843_m1 & NM_000193 & SHH & Sonic Hedgehog & -1.49 & -1.58 \\
Hs00745531_s1 & NM_002181 & IHH & Indian Hedgehog & -7.89 & -2.24 \\
Hs00368306_m1 & NM_021044 & DHH & Desert Hedgehog & $\mathbf{2 5 . 0 2}$ & $\mathbf{3 . 9 3}$ \\
Hs00181117_m1 & NM_000264 & PTCH1 & Patched 1 & -1.72 & -19.97 \\
Hs01085642_m1 & NM_001166292 & PTCH2 & Patched 2 & $\mathbf{2 . 0 3}$ & $\mathbf{7 . 4 9}$ \\
Hs00977641_m1 & NM_001243280 & ALCAM & $\begin{array}{l}\text { Activated leukocyte } \\
\text { cell adhesion molecule }\end{array}$ & -2.00 & -1.27 \\
Hs00900055_m1 & NM_001025366 & VEGFA & $\begin{array}{l}\text { Vascular endothelial } \\
\text { growth factor A }\end{array}$ & $\mathbf{1 . 9 6}$ & $\mathbf{2 . 3 9}$ \\
Hs00171558_m1 & NM_003254 & TIMP-1 & $\begin{array}{l}\text { TIMP } \\
\text { metallopeptidase }\end{array}$ & $\mathbf{5 . 8 0}$ & $\mathbf{5 . 0 0}$ \\
& & inhibitor 1 & & Zinc finger E-box \\
Hs00232783_m1 & NM_001128128 & ZEB1 & binding homeobox 1 & -1.33 & -9.85 \\
Hs00207691_m1 & NM_001171653 & ZEB2 & $\begin{array}{l}\text { Zinc finger E-box } \\
\text { binding homeobox 2 }\end{array}$ & $\mathbf{2 . 0 6}$ & $\mathbf{1 . 8 2}$ \\
\hline
\end{tabular}

Custom Taqman Assay in mRNA samples extracted from untreated and CPS-treated cells for $120 \mathrm{~h}$. Values represent fold differences of individual gene expression in CPS treated compared to untreated BC cells. The expression levels were normalized to the average $\mathrm{Ct}$ value of two housekeeping genes (GAPDH and $\beta$ actin) and calculated by the $\Delta \Delta \mathrm{Ct}$ method. In bold up-regulated genes. Data shown are representative of one out of three separate experiments.

Taken together, our results demonstrated that CPS-resistant 5637 and T24 BC cells showing the EMT phenotype display chemotherapeutic drug-resistance.

\section{DISCUSSION}

Herein, we demonstrated that CPS, by triggering autophagic cell survival, stimulates $\mathrm{BC}$ cells to undergo epithelial mesenchymal transition and to develop chemotherapeutic drug-resistance through the Hedgehog signalling pathway.

In CPS-treated BC cells, cellular energy imbalance resulting from ROS generation, alterations of ATP levels, mitochondrial depolarization and AMPK signalling pathway activation, promotes autophagy as demonstrated by the enhancement of LC3-II/LC3-I ratio and accumulation of $\mathrm{p} 62$ protein evaluated in CPS plus BAF-treated BC cells. We also demonstrated by using the ROS inhibitor NAC that the intracellular ROS production, triggered by CPS in $\mathrm{BC}$ cells, is responsible for the oxidative stress-induced autophagy, that started at $12 \mathrm{~h}$ and remained sustained until $72 \mathrm{~h}$. The time-dependent increase of $\mathrm{p} 62$ SQSTM1 protein expression was a consequence of enhanced transcription level as evidenced by qRT-PCR. Moreover, CPS treatment increased the expression of autophagic genes such as GABARAPL1 and MAP1LC3B associated with autophagic vesicles formation [28], IRGM and ULK1 engaged in the autophagy complex initiation [29], TNF $\alpha$ and PTEN, involved in autophagy induction [30,31].

Autophagy promotes stress-induced cell survival or autophagic cell death [10]. In this regard, we showed that CPS-induced autophagy mediates a pro-survival effect in 5637 and T24 BC cells. In fact a marked increase of necrotic cells was evident in BC cells treated with CPS in combination with the autophagic inhibitor BAF. In addition, knockdown of Beclin 1, that inhibits the CPS-induced autophagy, reduces the growth of BC cells. Similarly, it has been recently demonstrated that CPS-induced autophagy rescues breast carcinoma and osteosarcoma cells from death [11, 12]. Taken together, our findings indicated that CPS-stimulated autophagy acts as a mechanism counteracting cell death and contributing to the survival of $\mathrm{BC}$ cells.

The EMT is characterized by morphological changes from epithelial to spindle-shaped mesenchymal like cells, 
increased cell size, loss of cell adhesion as consequence of changes in integrin expression, in particular $\alpha_{5} \beta_{1}$ overexpression [15], increased invasiveness and expression of mesenchymal markers especially vimentin [32, 33]. CPS has been found to induce EMT in colon cancer cells [16], but no data on $\mathrm{BC}$ has been provided so far. To better clarify the effect of CPS in 5637 and T24 BC cells, we characterized the phenotype of CPS-resistant $\mathrm{BC}$ cells rescued by autophagy. CPS-treated BC cells show increased cell size and mesenchymal-like morphology, enhanced expression of vimentin, $\alpha_{5}$ and $\beta_{1}$ integrin subunits and integrin like kinase

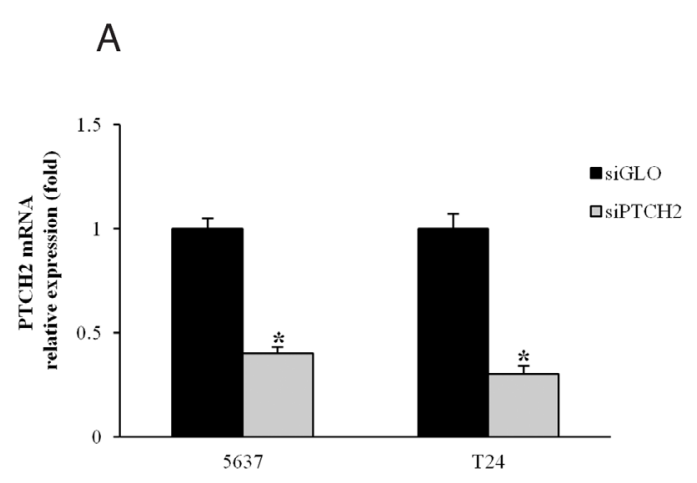

C
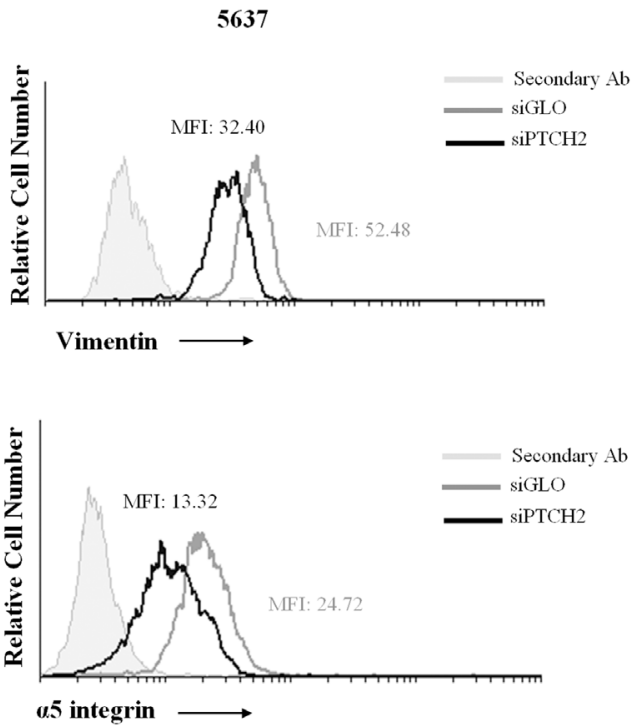

(ILK) and anti-apoptotic Bcl-2 proteins and downregulation of E-cadherin. The CPS-induced EMT-positive BC cells are actively replicating suggesting a possible involvement in bladder cancer relapse. In agreement with our results, it is well known that ILK activation is involved in survival, proliferation, motility, invasion, angiogenesis [34] and that ILK silencing inhibits EMT, cell growth and metastasis in $\mathrm{BC}$ cells [35]. In addition in $\mathrm{BC}$, increased $\mathrm{Bcl}-2$ proteins, that correlates with high pathologic stage, disease recurrence and mortality rate [36], may enhance the resistance to necrotic death and support the BC autophagic survival.

$\mathrm{B}$
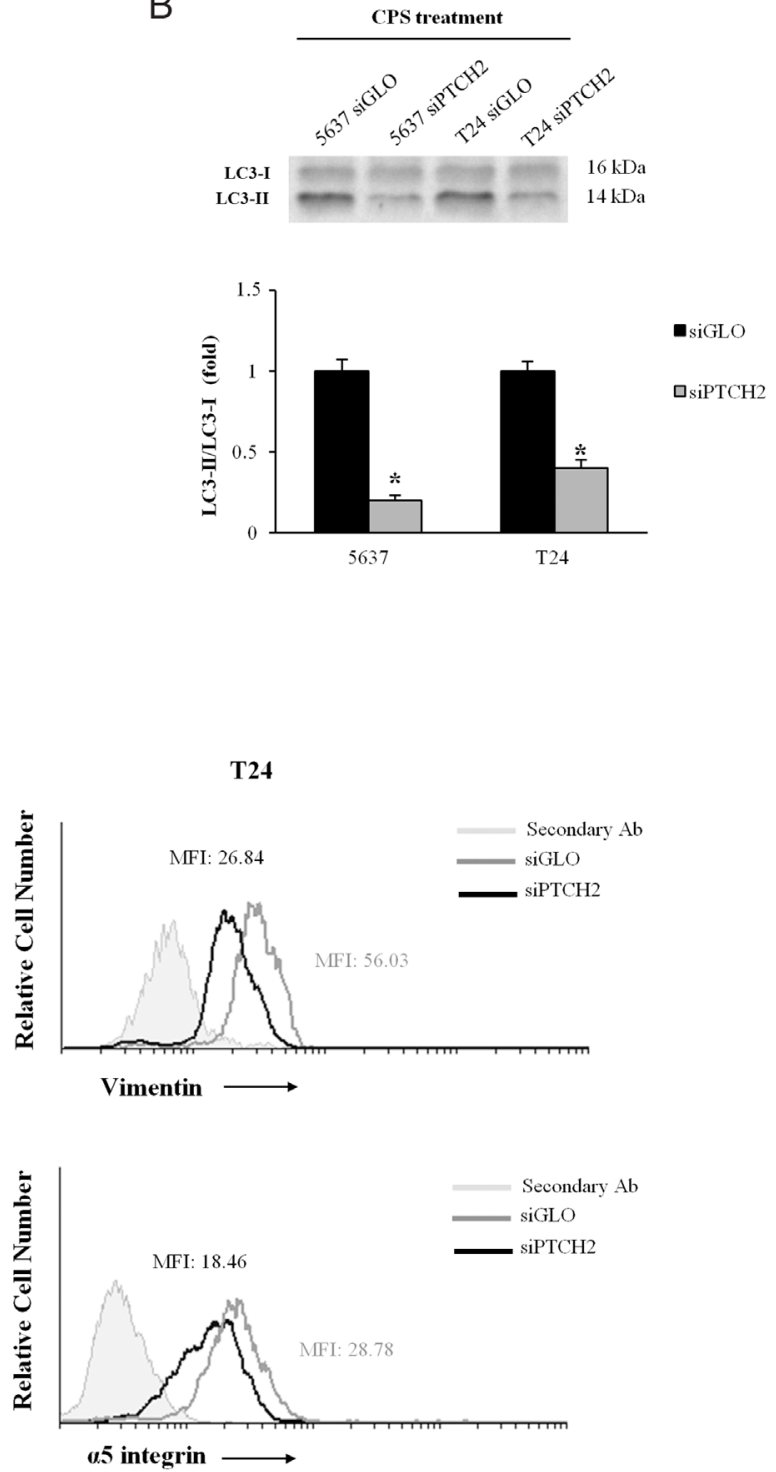

Figure 5: The Hedgehog signaling pathway is involved in the CPS-induced autophagy and EMT phenotype. A. PTCH2 mRNA expression, normalized to GAPDH levels, was evaluated in siGLO and siPTCH2 BC cells by qRT-PCR. *p $<0.01$ siPTCH2 vs siGLO $\mathrm{BC}$ cells. B. Lysates from siGLO and siPTCH2 BC cells treated for $72 \mathrm{~h}$ with CPS $(300 \mu \mathrm{M})$ were separated on $14 \%$ SDS-PAGE and probed with anti-LC3 Ab. Cropped blots are representative of one of three separate experiments. Bars represent the densitometric analysis, shown as the mean $\pm \mathrm{SD}$ of three different experiments, evaluated using siGLO cells as calibrator. ${ }^{*} \mathrm{p}<0.01$ CPS-treated siPTCH 2 vs CPS-treated siGLO cells. C. FACS analysis was performed in siGLO and siPTCH2 BC cells, treated with CPS $(300 \mu \mathrm{M})$ for $120 \mathrm{~h}$, stained with anti-vimentin and anti- $\alpha_{5}$ integrin subunit Abs followed by respective FITC-conjugated secondary Abs. One representative out of three independent experiments is shown. Numbers indicate the Mean Fluorescence Intensity (MFI). 
Activation of the Hedgehog pathway in human BC cells and its association with BC progression and clinical outcome have been recently reported [17, 37-39]. Herein, by qRT-PCR, we observed that exposure of BC cells to high dose of CPS for $120 \mathrm{~h}$, modulates the expression of different members of the Hedgehog signaling pathway. Thus, upregulation of $\mathrm{Dhh} / \mathrm{Ptch} 2 / \mathrm{Zeb} 2$, as well as downregulation of Shh and/or Ihh/Ptch1/Zeb1 transcripts were found in CPS-treated BC cells, as respect to control cells. In addition, the silencing of PTCH2 gene in $\mathrm{BC}$ cells inhibited the CPS-induced autophagy and reverted the EMT phenotype, as evaluated by the reduction of LC3-II, vimentin and $\alpha_{5}$ integrin subunit. Hedgehog $(\mathrm{Hh})$ signals acts as survival factor by maintaining the viability of UC cells and increased $\mathrm{Hh}$ activity is required for $\mathrm{BC}$ cell growth. Constitutive activation of different members (e.g. ligands and receptors) of the Hedgehog pathway

A

5637
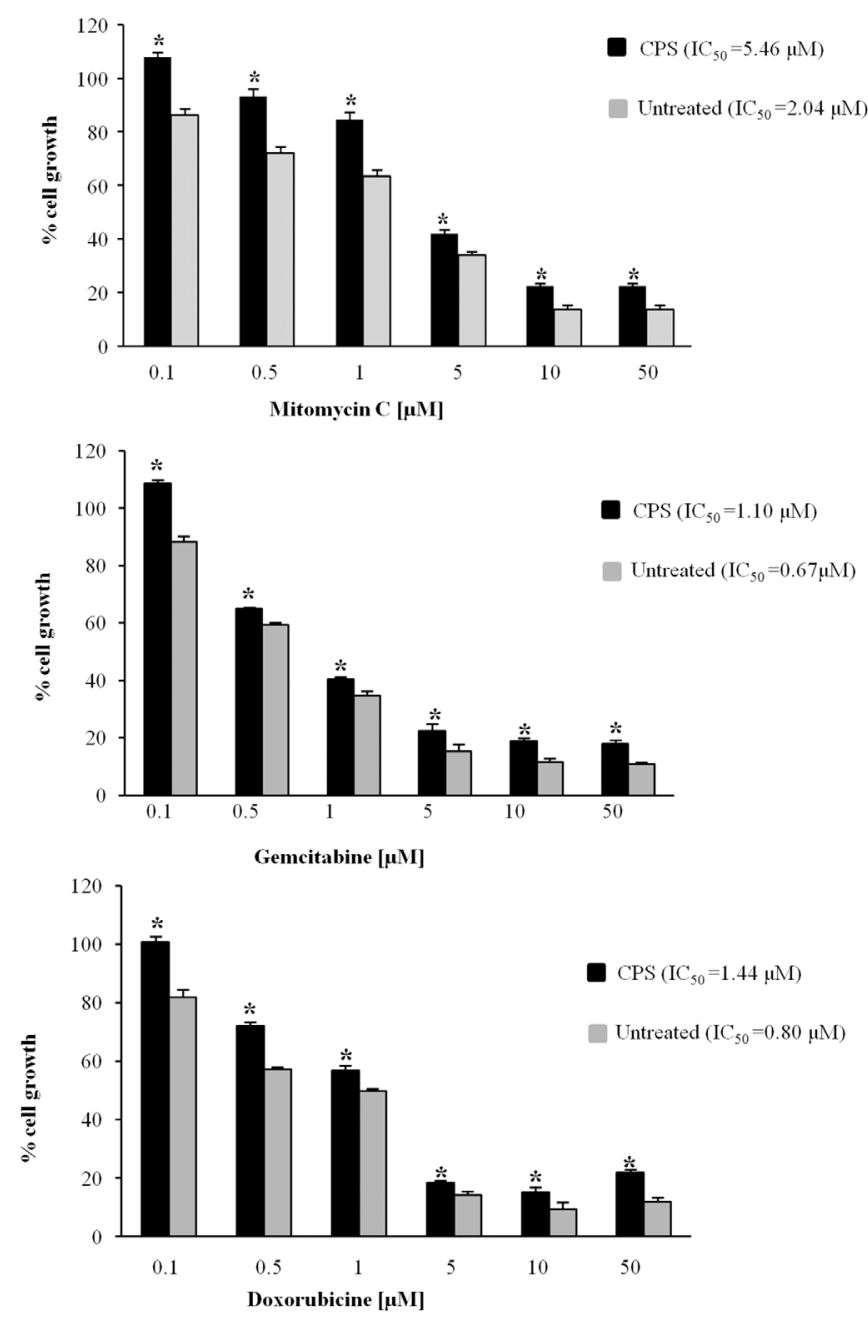

highly correlates with BC progression [17]. Recent evidence in HeLa cells showed that Ptch2 overexpression, increased LC3-II levels and autophagy, in the absence and presence of $\mathrm{BAF}$, and knockdown of $\mathrm{PTCH} 2$ reduced the LC3-II levels in basal and induced autophagy [40]. Increased PTCH2 mRNA expression correlates with poorer overall survival in muscle-invasive $\mathrm{BC}$ [37] and a functional link of $\mathrm{PTCH} 2$ in regulating the activation of Dhh pathway has been suggested [41]; moreover enhanced Dhh expression was associated with invasive prostate and bladder cancers and hormone-refractory behaviour [42]. In addition, overexpression of Zeb2, a transcription factor detected in infiltrating UC [43], that promotes the EMT [44] and regulates the expression of integrins [45], may be responsible for the increase of $\alpha_{5}$ integrin expression level in EMT-positive CPS-treated T24 and 5637 BC cells.

B

T24
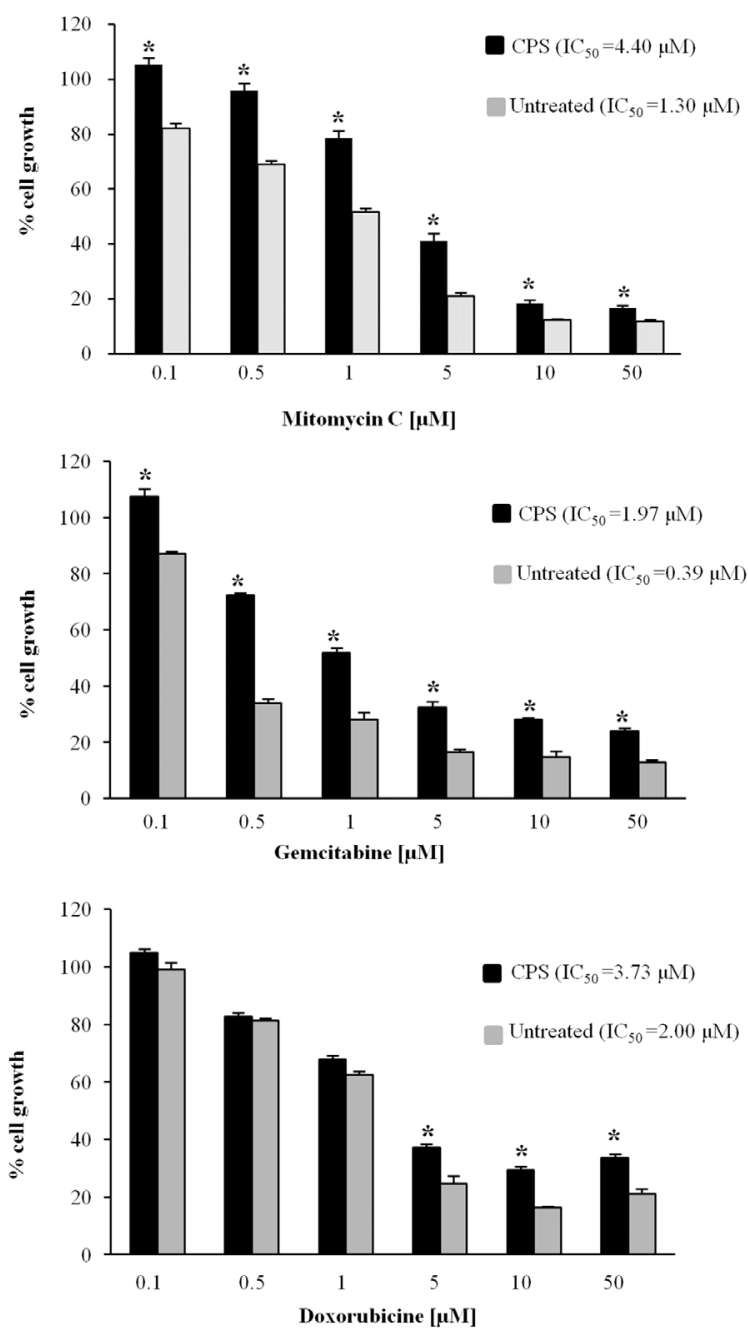

Figure 6: CPS-resistant BC cells characterized by EMT phenotype, show resistance to chemotherapeutic agents. A-B. $\mathrm{BC}$ cells treated with CPS for $120 \mathrm{~h}$ were detached, counted and plated for additional $48 \mathrm{~h}$ in medium supplemented with different doses of mitomycin $\mathrm{C}$, gemcitabine or doxorubicine. At the end of treatment MTT assays were performed. Data shown are the mean $\pm \mathrm{SE}$ of three independent experiments. ${ }^{*} \mathrm{p}<0.01 \mathrm{CPS}$-treated vs untreated $\mathrm{BC}$ cells. $\mathrm{IC}_{50}$ was calculated using GraphPad. 
We also found increased expression of EMT-related genes such as CD24, VEGFA, TIMP1 and decreased levels of activated cell adhesion (ALCAM/CD166) and CD44 molecules in BC cell lines treated with CPS. The CD24 and CD44 antigens mark distinct cell population in BC [46], and CD24 expression has been associated with a more aggressive phenotype, reduced survival and poor prognosis [47]. Metalloproteases and their inhibitors, TIMPs, play a pivotal role in BC progression. TIMP1 overexpression correlates with pathological stage and poor prognosis in $\mathrm{BC}$ and induces the phenotypic changes linked with increased vimentin levels [48]. Furthermore, ALCAM loss/downregulation is associated with a more invasive phenotype and poorer outcome in BC [49]. Since the key-role of VEGFA in vimentin expression promoting EMT changes [50] and chemoresistance [51] in BC cells, VEGFA overexpression may be partially responsible for the acquisition of the EMT phenotype and drug resistance found in CPS-treated BC cells.

The EMT regulates drug-resistance and invasion in BC cells [36], and EMT prevention increases the BC sensitivity to anti-neoplastic agents [14]. The development of chemoresistance during BC treatment prejudices the effects of the chemotherapy agents and is responsible for the high morbidity and mortality of $\mathrm{BC}$ in the world [52]. Here, we found that CPS-induced EMT in BC cells results in an increased drug-resistance of $\mathrm{BC}$ cells to the cytotoxic effects of mitomycin $\mathrm{C}$, gemcitabine and doxorubicine.

From a clinical point of view, it is now well established that the induction of autophagy interferes with the efficacy of cancer therapeutics [53]. In fact, recent studies reported increased chemoresistance in $\mathrm{BC}$ cells with concurrent up-regulation of autophagy related genes [54]. At this regard, at present, there is substantial evidence demonstrating the improved therapeutic effects by using the established cancer therapeutics agents in combination with autophagy inhibitors [53].

Overall, our results, showing that the escape of BC cells from CPS-induced death, by triggering the autophagic survival, Hedgehog pathway activation, EMT and chemotherapy drug resistance, are in line with these recent findings. Therefore the treatment of BC cells with CPS in combination with specific autophagic or EMT/Hedgehog pathway inhibitors, could represent an interesting new approach in BC therapy.

\section{MATERIALS AND METHODS}

\section{Cell lines}

5637 and T24 BC cell lines, purchased from LeibnizInstitute DSMZ (Braunschweig, Germany) on May 5, 2015 with authentication by DNA typing, were maintained in RPMI-1640 medium (Lonza Bioresearch, Basel, Switzerland) supplemented with $10 \%$ heat-inactivated fetal bovine serum, $2.5 \mathrm{mM} \mathrm{N}$-2-hydroxyethylpiperazine-
N'-2-ethanesulfonicacid (HEPES), 2 mM L-glutamine, $100 \mathrm{IU} / \mathrm{ml}$ of penicillin and $100 \mu \mathrm{g} / \mathrm{ml}$ of streptomycin (Lonza) at $37^{\circ} \mathrm{C}, 5 \% \mathrm{CO}_{2}$ and $95 \%$ humidity.

\section{Reagents}

Capsaicin (CPS, trans-8-methyl-N-vanillyl-6nonenamide) was purchased from Sigma Aldrich (MO, USA). The following antibodies (Abs) were used: anti-p62, anti-AMPK, anti-pAMPK, anti-ATG4C and anti-Beclin 1 (1:1000, Cell Signaling Technology, CO, USA), antimicrotubule-associated protein-1 ight chain 3 (LC3, $2 \mu \mathrm{g}$ / $\mathrm{ml}$, Novus Biologicals, CO, USA), horseradish peroxidase (HRP)-conjugated anti-glyceraldehyde-3-phosphate dehydrogenase (anti-GAPDH, 1:5000, Sigma Aldrich), anti- $\alpha_{5}$ integrin (1:25, Beckman Couture, FL, USA), anti- $\beta_{1}$ integrin (1:50, Santa Cruz Biotechnology, CA, USA), anti-Bcl2 (1:50, Bethyl Laboratories Inc, TX, USA), antiIntegrin linked kinase (ILK, 1:50, Bethyl Laboratories Inc), anti-vimentin (1:50, Merk Millipore, MA, USA), anti-E cadherin (1:50, Santa Cruz Biotechnology), antiBrdU (1:20, Becton Dickinson Biosciences, CA, USA). The following secondary Abs were used: HRP-conjugated donkey anti-rabbit $(1: 2000)$ and HRP-conjugated sheep anti-mouse (1:2000) from GE Healthcare Bio-Sciences (Uppsala, Sweden), FITC-conjugated anti-mouse Ab (1:40), FITC-conjugated anti-rabbit (1:40) and FITCconjugated donkey anti-goat (1:40) Abs were from Santa Cruz Biotechnology. 5,5,6,6-tetrachloro-1,1,3,3-tetraethyl benzimidazolylcarbocyanine iodide (JC-1, $10 \mu \mathrm{g} / \mathrm{ml}$ ) and Acridine Orange (AO $1 \mu \mathrm{g} / \mathrm{ml}$ ) were from Invitrogen (CA, USA). 20,70-Dichlorofluorescein diacetate (DCFDA, 10 $\mu \mathrm{g} / \mathrm{ml}$ ), dimethyl sulfoxide (DMSO, used as vehicle), $\mathrm{N}$ acetylcysteine (NAC, $10 \mathrm{mM}$ ), Diphenyleneiodonium chloride (DPI, 0.1 $\mathrm{MM}$ ), Rotenone (ROT, $1 \mu \mathrm{M}$ ), 5-bromo2-deoxyuridine (BrdU), propidium iodide (PI, $2 \mu \mathrm{g} / \mathrm{ml}$ ) and 3-(4,5-dimethylthiazol-2-yl)-2,5-diphenyltetrazolium bromide (MTT) were from Sigma Aldrich. Bafilomycin A1 (BAF, $25 \mathrm{nM}$ ) was from Labogen (Catania, Italy). Annexin V-FITC $(5 \mu \mathrm{l} / \mathrm{ml})$ was purchased from Enzo Life Sciences (NY, USA).

\section{Beclin 1 and PTCH2 gene silencing}

siGENOME SMARTpools for Beclin 1 (siBeclin 1), siCONTROL nontargeting siRNA (siGLO) used as negative control were purchased from Thermo ScientificDharmacon (CO, USA). For gene silencing experiments, 5637 and T24 cells were plated in a six well plate at the density of $3 \times 10^{4} / \mathrm{ml}$ and $160 \mathrm{pmol}$ of siBeclin 1 or siGLO was added to the wells for $48 \mathrm{~h}$, following the METAFECTENE SI PRO transfection protocol (Biontex Laboratories, CA, USA).

To knockdown PTCH2, the GeneSolution siRNA for PTCH2 (siPTCH2), negative control siRNA duplex (siGLO) and the HiPerfect Transfection reagent (Qiagen, CA, USA) were used following the Fast-forward 
Transfection protocol. Briefly 5637 and T24 cells were plated in a twenty-four well plate at the density of $5 \times 10^{4} /$ $\mathrm{ml}$ and siPTCH2 or siGLO at the concentration of $5 \mathrm{nM}$ were added to the wells for $48 \mathrm{~h}$. Then silenced cells were detached, counted and plated for MTT, western blot and FACS analyses.

\section{MTT assay}

The colorimetric MTT assay was used to evaluate cell viability. Briefly, 5637 and T24 BC cells $\left(3 \times 10^{4} / \mathrm{ml}\right)$ were seeded into 96-well plates and cultured with CPS $(300 \mu \mathrm{M})$ for 72 and $120 \mathrm{~h}$ at $37^{\circ} \mathrm{C}, 5 \% \mathrm{CO}_{2}$. At the end of treatment, $0.8 \mathrm{mg} / \mathrm{ml}$ of MTT was added to the samples and incubated for $3 \mathrm{~h}$. Then the supernatants were discarded and coloured formazan crystals, dissolved with $100 \mu \mathrm{l} /$ well of DMSO, were read by an enzyme-linked immunosorbent assay reader (BioTek Instruments, VT, USA). Four replicates were used for each treatment and data were represented as the average of at least three separate experiments. In some experiments, BC cells silenced or not for Beclin 1, were treated with CPS $(300 \mu \mathrm{M})$ for $72 \mathrm{~h}$ before to perform the MTT assay. Finally to assess drug resistance, the assay was performed in $\mathrm{BC}$ cells, that after treatment with CPS for $120 \mathrm{~h}$, were detached, counted, plated at $3 \times 10^{4} / \mathrm{ml}$ in a 96 well plate and treated for additional $48 \mathrm{~h}$ with different doses (from 0.01 to $50 \mu \mathrm{M}$ ) of mitomycin $\mathrm{C}$, gemcitabine and doxorubicine. The half maximal inhibitory concentration $\left(\mathrm{IC}_{50}\right)$ was determined using GraphPad (GraphPad Software, CA, USA).

\section{Cell death analysis}

To evaluate cell death, 5637 and T24 cells $\left(3 \times 10^{4} /\right.$ $\mathrm{ml})$, untreated or treated for different times (24, 48 and 72 h) with CPS $(300 \mu \mathrm{M})$ alone or in combination with BAF $(25 \mathrm{nM})$, were stained with PI. To assess cell death type, $\mathrm{BC}$ cells treated for $72 \mathrm{~h}$ with CPS alone or in combination with BAF were also double stained with Annexin V-FITC and PI. The percentage of positive cells determined over 10000 events was analysed on a FACScan cytofluorimeter using the CellQuest software.

\section{AVO detection}

5637 and T24 BC cells $\left(3 \times 10^{4} / \mathrm{ml}\right)$ were seeded into 24-well plates and treated or not with CPS $(300 \mu \mathrm{M})$ for $48 \mathrm{~h}$. Cells were then washed with medium, stained with AO $(1 \mu \mathrm{g} / \mathrm{ml})$ for $15 \mathrm{~min}$ and analyzed on a FACScan cytofluorimeter using the FL1 and FL3 fluorescence. The percentage of positive cells determined over 10000 events was evaluated using the CellQuest software.

\section{Western blot analysis}

5637 and T24 cells, untreated or treated CPS (300 $\mu \mathrm{M}$ ) for different times, were lysed in a lysis-buffer containing protease inhibitor cocktail (Sigma Aldrich).
Lysates were separated on sodium dodecyl sulphate polyacrylamide gel (9 and 14\%) and transferred. After blocking with 5\% low-fat dry milk in phosphate-buffered saline (PBS) $0.1 \%$ Tween 20 for $1 \mathrm{~h}$, blots were incubated with the primary Abs: anti-LC3, anti-p62, anti-AMPK, anti-pAMPK, anti-Atg4C, or anti-GAPDH, followed by the appropriate HRP-conjugated antibodies. To assess the autophagic flux, cells were treated with CPS alone or in combination with BAF $(25 \mathrm{nM})$. The LC3 conversion was also assessed in BC cells treated for $72 \mathrm{~h}$ with CPS $(300 \mu \mathrm{M})$ alone or in combination with NAC (10 mM). In addition, western blot was performed in lysates from siGLO or siBeclin $1 \mathrm{BC}$ cells, treated or not with CPS $(300 \mu \mathrm{M})$ for $72 \mathrm{~h}$, using anti-Beclin 1 or anti-LC3 Abs, to evaluate silencing efficacy and autophagy respectively. Moreover LC3 levels were investigated in lysates from siGLO or siPTCH2 BC cells treated, as above described, with CPS. The detection was performed using LiteAblot Turbo (EuroClone, Milano, Italy) and densitometric analysis was carried out evaluating three independent experiments by Chemi-Doc using Quantity One software (Bio-Rad, CA, USA). GAPDH levels were used as loading control.

\section{ROS production}

5637 and T24 BC cells $\left(3 \times 10^{4} / \mathrm{ml}\right)$ were seeded into 24-well plates and cultured for 4, 8, 12, 20 and $24 \mathrm{~h}$ with CPS $(300 \mu \mathrm{M})$ or vehicle. Cells were washed with PBS, pulsed with DCFDA for $10 \mathrm{~min}$ at $37^{\circ} \mathrm{C}, 5 \% \mathrm{CO}_{2}$, and analyzed by FACScan cytofluorimeter using the CellQuest software. In some experiments, ROS production was assessed in BC cells treated for $24 \mathrm{~h}$ with CPS $(300 \mu \mathrm{M})$ alone or in combination with NAC $(10 \mathrm{mM})$, ROT $(1 \mu \mathrm{M})$ and DPI $(0.1 \mu \mathrm{M})$.

\section{Mitochondrial transmembrane potential ( $\Delta \Psi \mathrm{m})$}

$\Delta \Psi \mathrm{m}$ was evaluated by JC-1 staining. 5637 and T24 BC cells $\left(3 \times 10^{4} / \mathrm{ml}\right)$, seeded into 24 -well plates, were treated with CPS $(300 \mu \mathrm{M})$ or vehicle for different times $(0,6,8,12$ and $24 \mathrm{~h})$ and then incubated for $10 \mathrm{~min}$ at room temperature with JC-1. JC-1 was excited by an argon laser (488 nm); green (530 nrn)/red (>570 nrn) emission fluorescence was collected simultaneously. Carbonyl cyanide chlorophenylhydrazone protonophore, a mitochondrial uncoupler was used as positive control (data not shown). Samples were analyzed by a FACScan cytofluorimeter using the CellQuest software; fluorescence intensity was expressed in arbitrary units on logarithmic scale.

\section{Measurement of ADP/ATP ratio}

5637 and T24 BC cells $\left(3 \times 10^{4} / \mathrm{ml}\right)$ were seeded into 96-well plates and cultured with CPS $(300 \mu \mathrm{M})$ for 12 $\mathrm{h}$ at $37^{\circ} \mathrm{C}, 5 \% \mathrm{CO}_{2}$. At the end of treatment, ADP/ATP ratio was measured by the EnzyLight ADP/ATP Ratio Assay Kit (BioAssay Systems, CA, USA) following the 
instructions. Bioluminescence was acquired by FluoStar OMEGA luminometer (BMG LABTECH GmbH, Ortenberg, Germany).

\section{Gene expression analysis}

Total RNA was extracted from 5637 and T24 BC cells, treated for $12 \mathrm{~h}$ with CPS $(300 \mu \mathrm{M})$ or vehicle, with the RNeasy Mini Kit (Qiagen) and reverse transcribed using the Reaction Ready first strand cDNA kit (Superarray Bioscience Corporation, MD, USA). Quantitative Real Time PCR (qRT-PCR) was performed using the IQ5 Multicolor Real-time PCR detection system (Bio-Rad), the RT2 real-time SYBR green PCR Mix and the Human Autophagy plates according to the protocol (Qiagen).

In addition, total RNA from $\mathrm{BC}$ cells, untreated or treated with CPS $(300 \mu \mathrm{M})$ for $120 \mathrm{~h}$, was extracted with the RNeasy Mini Kit (Qiagen), and cDNA was synthesized using the High-Capacity cDNA Archive Kit (Applied Biosystems, PA, USA) according to the manufacturer's instructions. The EMT pathway was analysed by qRTPCR using a Custom Taqman assay (Thermofisher Scientific, MA, USA). Moreover, to evaluate the efficacy of PTCH2 silencing, qRT-PCR was performed using ddPCR GEX Assay for PTCH2 and GAPDH (Bio-Rad) and the QuantiFast Multiplex PCR Master Mix (Qiagen).

\section{Fluorescence-activated cell sorting analysis}

5637 and T24 BC cells, plated in 24 well plate at the concentration of $3 \times 10^{4} / \mathrm{ml}$, were treated with vehicle or CPS $(300 \mu \mathrm{M})$ for $120 \mathrm{~h}$. Then cells were detached, counted and fixed with $4 \%$ paraformaldehyde for $10 \mathrm{~min}$ at room temperature. After washing in staining buffer $(0.1 \%$ sodium azide, $1 \%$ FBS in PBS) cells were stained with anti- $\beta_{1}$ and anti- $\alpha_{5}$ integrin subunits followed by FITCconjugated secondary $\mathrm{Ab}$. In addition $\mathrm{BC}$ cells were also permeabilized using Perm solution (1\% saponin, $0.1 \%$ sodium azide, 1\% FBS in PBS) and labelled with anti-E cadherin, anti-vimentin, anti-ILK and anti-Bcl2 followed by respective FITC-conjugated secondary Abs. In some experiments, the expression of vimentin and $\alpha_{5}$ integrin subunit was valuated in siGLO and siPTCH2 cells after treatment for $120 \mathrm{~h}$ with CPS. Samples were analysed by a FACScan cytofluorimeter using the CellQuest software (Becton Dickinson).

\section{Morphological analysis}

5637 and T24 BC cells, plated in 24 well plate at the concentration of $3 \times 10^{4} / \mathrm{ml}$, were treated with vehicle or CPS $(300 \mu \mathrm{M})$ for $120 \mathrm{~h}$. Then morphological analysis was assessed by citofluorimetric analysis using forward scatter parameter and by light microscope at X40 magnification using a BX51 microscope (Olympus, Milan, Italy).

\section{BrdU incorporation}

5637 and T24 BC cells, plated in 24 well plate at the concentration of $3 \times 10^{4} / \mathrm{ml}$, were treated with CPS $(300 \mu \mathrm{M})$ for $120 \mathrm{~h}$. Then cells were detached, counted and plated at the concentration of $3 \times 10^{4} / \mathrm{ml}$ in a 6 well plate. The day after, BrdU $(20 \mu \mathrm{M})$ was added for additional $24 \mathrm{~h}$. At the end of the BrdU incorporation BC cells were fixed using $70 \%$ ice-cold ethanol and stained with anti $\mathrm{BrdU} \mathrm{Ab}$ (1:20) followed by FITC-conjugated secondary $\mathrm{Ab}$ (1:40). Samples were analysed by a FACScan cytofluorimeter using the CellQuest software. Fluorescence intensity was expressed in arbitrary units on logarithmic scale.

\section{Statistical analysis}

The statistical significance was determined by Student's t-test and Anova. No statistical significant difference was found between untreated and vehicle (DMSO)-treated cells or comparing different times of vehicle-treatment each other.

\section{CONFLICTS OF INTEREST}

Authors declare no conflicts of interest.

\section{SUMMARY}

We demonstrated that capsaicin (CPS) induces autophagic survival in bladder cancer cells that undergo epithelial mesenchymal transition and acquire a more aggressive phenotype and drug-resistance by involving the Hedgehog signaling pathway.

\section{REFERENCES}

1. Pliarchopoulou K, Laschos K, Pectasides D. Current chemotherapeutic options for the treatment of advanced bladder cancer: a review. Urol Oncol. 2013; 31: 294-302.

2. Sharma SK, Vij AS, Sharma M. Mechanisms and clinical uses of capsaicin. Eur J Pharmacol. 2013; 720: 55-62.

3. Bley K, Boorman G, Mohammad B, McKenzie D, Babbar S. A comprehensive review of the carcinogenic and anticarcinogenic potential of capsaicin. Toxicol Pathol. 2012; 40: 847-873.

4. Amantini C, Mosca M, Nabissi M, Lucciarini R, Caprodossi S, Arcella A, Giangaspero F, Santoni G. Capsaicin-induced apoptosis of glioma cells is mediated by TRPV1 vanilloid receptor and requires p38 MAPK activation. J Neurochem. 2007; 102: 977-990.

5. Ip SW, Lan SH, Lu HF, Huang AC, Yang JS, Lin JP, Huang HY, Lien JC, Ho CC, Chiu CF, Wood W, Chung JG. Capsaicin mediates apoptosis in human nasopharyngeal carcinoma NPC-TW 039 cells through mitochondrial 
depolarization and endoplasmic reticulum stress. Hum Exp Toxicol. 2012; 31: 539-549.

6. Tsou MF, Lu HF, Chen SC, Wu LT, Chen YS, Kuo $\mathrm{HM}$, Lin SS, Chung JG. Involvement of Bax, Bcl-2, $\mathrm{Ca}^{2+}$ and caspase-3 in capsaicin-induced apoptosis of human leukemia HL-60 cells. Anticancer Res. 2006; 26: 1965-1971.

7. Ramos-Torres Á, Bort A, Morell C, Rodríguez-Henche $\mathrm{N}$, Díaz-Laviada I. The pepper's natural ingredient capsaicin induces autophagy blockage in prostate cancer cells. Oncotarget. 2016; 7: 1569-1583. doi: 10.18632/ oncotarget.6415.

8. Amantini C, Ballarini P, Caprodossi S, Nabissi M, Morelli MB, Lucciarini R, Cardarelli MA, Mammana G, Santoni G. Triggering of transient receptor potential vanilloid type 1 (TRPV1) by capsaicin induces Fas/CD95-mediated apoptosis of urothelial cancer cells in an ATM-dependent manner. Carcinogenesis. 2009; 30: 1320-1329.

9. Yang ZH, Wang XH, Wang HP, Hu LQ, Zheng XM, Li SW. Capsaicin mediates cell death in bladder cancer T24 cells through reactive oxygen species production and mitochondrial depolarization. Urology. 2010; 75: 735-741.

10. Baehrecke EH. Autophagy: dual roles in life and death? Nat Rev Mol Cell Biol. 2005; 6: 505-510.

11. Yoon JH, Ahn SG, Lee BH, Jung SH, Oh SH. Role of autophagy in chemoresistance: regulation of the ATMmediated DNA-damage signaling pathway through activation of DNA-PKcs and PARP-1. Biochem Pharmacol. 2012; 83: 747-757.

12. Chien CS, Ma KH, Lee HS, Liu PS, Li YH, Huang YS, Chueh SH. Dual effect of capsaicin on cell death in human osteosarcoma G292 cells. Eur J Pharmacol. 2013; 718: 350-360.

13. Huang KH, Kuo KL, Ho IL, Chang HC, Chuang YT, Lin WC, Lee PY, Chang SC, Chiang CK, Pu YS, Chou CT, Hsu CH, Liu SH. Celecoxib-induced cytotoxic effect is potentiated by inhibition of autophagy in human urothelial carcinoma cells. PLoS One. 2013; 8: e82034.

14. Yang J, Yu H, Shen M, Wei W, Xia L, Zhao P. N1-guanyl1,7-diaminoheptane sensitizes bladder cancer cells to doxorubicin by preventing epithelial-mesenchymal transition through inhibition of eukaryotic translation initiation factor 5A2 activation. Cancer Sci. 2014; 105: 219-227.

15. Nam EH, Lee Y, Moon B, Lee JW, Kim S.Twist1 and AP-1 cooperatively upregulate integrin $\alpha_{5}$ expression to induce invasion and the epithelial-mesenchymal transition. Carcinogenesis. 2015; 36: 327-337.

16. Yang J, Li TZ, Xu GH, Luo BB, Chen YX, Zhang T. Low-concentration capsaicin promotes colorectal cancer metastasis by triggering ROS production and modulating Akt/mTOR and STAT-3 pathways. Neoplasma. 2013; 60: 364-372.

17. Fei DL, Sanchez-Mejias A, Wang Z, Flaveny C, Long J, Singh S, Rodriguez-Blanco J, Tokhunts R, Giambelli C,
Briegel KJ, Schulz WA, Gandolfi AJ, Karagas M et al. Hedgehog signaling regulates bladder cancer growth and tumorigenicity. Cancer Res. 2012; 72: 4449-4458.

18. Islam SS, Mokhtari RB, Noman AS, Uddin M, Rahman MZ, Azadi MA, Zlotta A, van der Kwast T, Yeger H, Farhat WA. Sonic hedgehog (Shh) signaling promotes tumorigenicity and stemness via activation of epithelialto-mesenchymal transition (EMT) in bladder cancer. Mol Carcinog. 2016; 55: 537-551.

19. McMahon AP. More surprises in the Hedgehog signaling pathway. Cell. 2000; 100: 185-188.

20. Puissant A, Fenouille N, Auberger P. When autophagy meets cancer through p62/SQSTM1. Am J Cancer Res. 2012; 2: 397-413.

21. Alexander A, Cai SL, Kim J, Nanez A, Sahin M, MacLean KH, Inoki K, Guan KL, Shen J, Person MD, Kusewitt D, Mills GB, Kastan MB, Walker CL. ATM signals to TSC2 in the cytoplasm to regulate mTORC1 in response to ROS. Proc Natl Acad Sci U S A. 2010; 107: 4153-4158.

22. Hail N Jr, Lotan R. Examining the role of mitochondrial respiration in vanilloid-induced apoptosis. J Natl Cancer Inst. 2002; 94: 1281-1292.

23. Farfariello V, Amantini C, Santoni G. Transient receptor potential vanilloid 1 activation induces autophagy in thymocytes through ROS-regulated AMPK and Atg4C pathways. J Leukoc Biol. 2012; 92: 421-431.

24. Lin EH, Kao YR, Lin CA, Kuo TY, Yang SP, Hsu CF, Chou TY, Ho CC, Wu CW. Hedgehog pathway maintains cell survival under stress conditions, and drives drug resistance in lung adenocarcinoma. Oncotarget. 2016; 7:24179-24193. doi: 10.18632/oncotarget.8253.

25. Zhang Y, Liu W, He W, Zhang Y, Deng X, Ma Y, Zeng J, Kou B. Tetrandrine reverses epithelial-mesenchymal transition in bladder cancer by downregulating Gli-1. Int J Oncol. 2016; 48: 2035-0242.

26. Xiao Q, Yang Y, Qin Y, He YH, Chen KX, Zhu JW, Zhang GP, Luo JD. AMP-activated protein kinase-dependent autophagy mediated the protective effect of sonic hedgehog pathway on oxygen glucose deprivation-induced injury of cardiomyocytes. Biochem Biophys Res Commun. 2015; 457: 419-425.

27. Shang Y, Cai X, Fan D. Roles of epithelial-mesenchymal transition in cancer drug resistance. Curr Cancer Drug Targets. 2013; 13: 915-929.

28. Slobodkin MR, Elazar Z. The Atg8 family: multifunctional ubiquitin-like key regulators of autophagy. Essays Biochem. 2013; 55: 51-64.

29. Chauhan S, Mandell MA, Deretic V. IRGM governs the core autophagy machinery to conduct antimicrobial defense. Mol Cell. 2015; 58: 507-521.

30. Djavaheri-Mergny M, Amelotti M, Mathieu J, Besançon F, Bauvy C, Souquère S, Pierron G, Codogno P. NF-kappaB activation represses tumor necrosis factor-alpha-induced autophagy. J Biol Chem. 2006; 281: 30373-30382. 
31. De Amicis F, Aquila S, Morelli C, Guido C, Santoro M, Perrotta I, Mauro L, Giordano F, Nigro A, Andò S, Panno ML. Bergapten drives autophagy through the up-regulation of PTEN expression in breast cancer cells. Mol Cancer. 2015; $14: 130$.

32. Lamouille S, Derynck R. Cell size and invasion in TGFbeta-induced epithelial to mesenchymal transition is regulated by activation of the mTOR pathway. J Cell Biol. 2007; 178: 437-451.

33. Gomes LR, Terra LF, Sogayar MC, Labriola L. Epithelialmesenchymal transition: implications in cancer progression and metastasis. Curr Pharm Biotechnol. 2011; 12: 1881-1890.

34. McDonald PC, Fielding AB, Dedhar S. Integrin-linked kinase--essential roles in physiology and cancer biology. $\mathrm{J}$ Cell Sci. 2008; 121:3121-3132.

35. Matsui Y, Assi K, Ogawa O, Raven PA, Dedhar S, Gleave ME, Salh B, So AI. The importance of integrin-linked kinase in the regulation of bladder cancer invasion. Int $\mathrm{J}$ Cancer. 2012; 130: 521-531.

36. Karam JA, Lotan Y, Karakiewicz PI, Ashfaq R, Sagalowsky AI, Roehrborn CG, Shariat SF. Use of combined apoptosis biomarkers for prediction of bladder cancer recurrence and mortality after radical cystectomy. Lancet Oncol. 2007; 8: 128-136.

37. Pignot G, Vieillefond A, Vacher S, Zerbib M, Debre B, Lidereau R, Amsellem-Ouazana D, Bieche I. Hedgehog pathway activation in human transitional cell carcinoma of the bladder. Br J Cancer. 2012; 106: 1177-1186.

38. He HC, Chen JH, Chen XB, Qin GQ, Cai C, Liang YX, Han ZD, Dai QS, Chen YR, Zeng GH, Zhu JG, Jiang FN, Zhong WD. Expression of hedgehog pathway components is associated with bladder cancer progression and clinical outcome. Pathol Oncol Res. 2012; 18: 349-355.

39. Shigemura K, Fujisawa M. Hedgehog signaling and urological cancers. Curr Drug Targets. 2015; 16: 258-271.

40. Jimenez-Sanchez M1, Menzies FM, Chang YY, Simecek N, Neufeld TP, Rubinsztein DC. The Hedgehog signalling pathway regulates autophagy. Nat Commun. 2012; 3: 1200.

41. Carpenter D, Stone DM, Brush J, Ryan A, Armanini M, Frantz G, Rosenthal A, de Sauvage FJ. Characterization of two patched receptors for the vertebrate hedgehog protein family. Proc Natl Acad Sci U S A. 1998; 95: 13630-13634.

42. Azoulay S, Terry S, Chimingqi M, Sirab N, Faucon H, Gil Diez de Medina S, Moutereau S, Maillé P, Soyeux P, Abbou C, Salomon L, Vacherot F et al. Comparative expression of Hedgehog ligands at different stages of prostate carcinoma progression. J Pathol. 2008; 216: 460-470.

43. Lee H, Jun SY, Lee YS, Lee HJ, Lee WS, Park CS. Expression of miRNAs and ZEB1 and ZEB2 correlates with histopathological grade in papillary urothelial tumors of the urinary bladder. Virchows Arch. 2014; 464: 213-220.

44. McConkey DJ, Choi W, Marquis L, Martin F, Williams MB, Shah J, Svatek R, Das A, Adam L, Kamat A, SiefkerRadtke A, Dinney C. Role of epithelial-to-mesenchymal transition (EMT) in drug sensitivity and metastasis in bladder cancer. Cancer Metastasis Rev. 2009; 28: 335-344.

45. Nam EH, Lee Y, Park YK, Lee JW, Kim S. ZEB2 upregulates integrin $\alpha_{5}$ expression through cooperation with $\mathrm{Sp} 1$ to induce invasion during epithelial-mesenchymal transition of human cancer cells. Carcinogenesis. 2012; 33: 563-571.

46. Hofner T, Macher-Goeppinger S, Klein C, Schillert A, Eisen C, Wagner S, Rigo-Watermeier T, Baccelli I, Vogel V, Trumpp A, Sprick MR. Expression and prognostic significance of cancer stem cell markers CD24 and CD44 in urothelial bladder cancer xenografts and patients undergoing radical cystectomy. Urol. Oncol. 2014; 32: 678-686.

47. Liu C, Zheng S, Shen H, Xu K, Chen J, Li H, Xu Y, Xu A, Chen B, Kaku H, Nasu Y, Kumon H, Huang P, et al. Clinical significance of CD24 as a predictor of bladder cancer recurrence. Oncol Lett. 2013; 6: 96-100.

48. Yano A, Nakamoto T, Hashimoto K, Usui T. Localization and expression of tissue inhibitor of metalloproteinase-1 in human urothelial cancer. J Urol. 2002; 167: 729-734.

49. Ofori-Acquah SF, King JA. Activated leukocyte cell adhesion molecule: a new paradox in cancer. Transl. Res. 2008; 151: 122-128.

50. Huang YJ, Qi WX, He AN, Sun YJ, Shen Z, Yao Y. Prognostic value of tissue vascular endothelial growth factor expression in bladder cancer: a meta- analysis. Asian Pac J Cancer Prev. 2013; 14: 645-649.

51. Li Y, Yang X, Su LJ, Flaig TW. VEGFR and EGFR inhibition increases epithelial cellular characteristics and chemotherapy sensitivity in mesenchymal bladder cancer cells. Oncol Rep. 2010; 24: 1019-1028.

52. Takeuchi A, Shiota M, Tatsugami K, Yokomizo A, Tanaka S, Kuroiwa K, Eto M, Naito S. p300 mediates cellular resistance to doxorubicin in bladder cancer. Mol Med Rep. 2012; 5: 173-176.

53. Wang C, Hu Q, Shen HM. Pharmacological inhibitors of autophagy as novel cancer therapeutic agents. Pharmacol Res. 2016; 105: 164-175.

54. Mani J, Vallo S, Rakel S, Antonietti P, Gessler F, Blaheta R, Bartsch G, Michaelis M, Cinatl J, Haferkamp A, Kögel D. Chemoresistance is associated with increased cytoprotective autophagy and diminished apoptosis in bladder cancer cells treated with the BH3 mimetic (-)-Gossypol (AT-101). BMC Cancer. 2015; 15: 224. 